(a) CrossMark

NEOPLASTIC DISEASE

\title{
Overexpression of Ephrin A3 Receptor in Canine Prostatic Carcinoma
}

\author{
G. Hood ${ }^{*}$, R. Laufer-Amorim ${ }^{\dagger}$, G. E. Fonseca-Alves ${ }^{\dagger}$ and G. Palmieri ${ }^{*}$ \\ * School of Veterinary Science, The University of Queensland, Gatton Campus, Gatton, Queensland, Australia and ${ }^{\dagger}$ School of \\ Veterinary Medicine and Animal Science, University Estadual Paulista, Botucatu, São Paulo, Brazil
}

\begin{abstract}
Summary
Ephrin A3 (EphA3), a member of the ephrin receptor tyrosine kinase family, is involved in a variety of functions in normal cells, especially during embryonic development, and alterations in its expression profile have been observed in several human cancers. However, there are no reports of the expression of EphA3 in normal, hyperplastic or neoplastic canine prostate tissue or in other types of canine tumours. Six normal, 15 hyperplastic and 21 neoplastic canine prostates were examined immunohistochemically with a polyclonal antibody specific for human EphA3. The percentage of positive cells in all prostatic carcinomas was increased, with a mean of $89.28 \pm 5.18 \%$ compared with normal $(9.17 \pm 6.72 \%)$ and hyperplastic prostates $(20.00 \pm 8.28 \%)$. EphA3 expression was not correlated with the histological subtypes of prostate cancer or with the Gleason score. The increase in EphA3 expression in canine prostatic carcinomas suggests the involvement of this receptor in prostatic carcinogenesis and its potential use as a target for new therapeutic strategies.
\end{abstract}

(c) 2016 Elsevier Ltd. All rights reserved.

Keywords: cancer; dog; EphA3; prostate

\section{Introduction}

Prostatic carcinoma (PC) in dogs is a highly aggressive cancer, characterized by a high rate of metastasis at presentation (Cornell et al., 2000). The prognosis is considered poor and most affected dogs are not treated due to the poor quality of life. Radical prostatectomy is usually associated with a very high incidence of postoperative urinary incontinence (Goldsmid and Bellenger, 1991). Radiotherapy has been attempted in combination with surgery, but with disappointing results and severe adverse effects (Turrel, 1987). No effective chemotherapeutic protocols are available for the treatment of PC in dogs. Therefore, research to develop better treatment options and, possibly, translation of new and successful therapeutic strategies already available in human oncology is needed.
With 16 members, the ephrin receptor family is the largest family of tyrosine kinase receptors and it is of increasing interest in developmental therapeutics. ephrin receptors are divided into two groups, A and $\mathrm{B}$, based on sequence homology and binding affinities to A or B class ephrin ligands (Pasquale, 2005). They are expressed widely during embryogenesis and regulate developmental processes such as axon guidance, angiogenesis and boundary formation (Pasquale, 2008). Many of the effects are mediated by signalling cascades modulating cell adhesion or cell movement, although they may also control cell survival, proliferation and differentiation (Himanen et al., 2007). The most promising molecule as tumour marker and potential therapeutic target in cancer, ephrin A3 (EphA3), is highly expressed at various stages of embryonic development of the brain and spinal cord, lungs, kidney, heart and musculature (Kilpatrick et al., 1996). After the embryonic period, its expression declines, being usually low, if detectable at all, in 
adults. However, EphA3 becomes re-expressed in a wide range of epithelial and mesenchymal tumours, and often correlates with a more aggressive behaviour and poor prognosis (Janes et al., 2014). During carcinogenesis, EphA3 plays an important role in a variety of biological functions, such as tumour cell proliferation, angiogenesis and tumour progression (Keane et al., 2012). The role of EphA3 in canine oncology has not been investigated, and even in men, the number of studies focussing on this molecule in prostate cancer is limited (Fox et al., 2006; Singh et al., 2008; Wu et al., 2014).

Therefore, the aim of the present study was to evaluate the immunohistochemical expression and distribution of EphA3 in normal, hyperplastic and neoplastic canine prostates and the potential association with the biological behaviour and the acquisition of an aggressive phenotype.

\section{Materials and Methods}

Samples and Histopathology

Forty-two, formalin-fixed and paraffin wax-embedded canine prostatic samples were selected from the archive of the diagnostic pathology service of the School of Veterinary Science, The University of Queensland, Australia $(n=36)$, and the Universidade Estadual Paulista, Brazil $(n=6)$. Sections $(5 \mu \mathrm{m})$ were stained with haematoxylin and eosin (HE) for histopathological examination. The samples were classified as normal prostates, benign prostatic hyperplasia $(\mathrm{BPH})$ and prostatic carcinoma (PC). The diagnosis of $\mathrm{PC}$ was limited to those cases showing no evidence of urinary bladder involvement. PCs were classified according to the growth patterns described by the human WHO classification of tumours of the urinary system and male genital organs (Eble et al., 2004) and recently adapted to canine PCs (Palmieri et al., 2014). Gleason grading was performed according to the 2005 International Society for Urological Pathology modified grading system (Epstein et al., 2005), recently described in dogs (Palmieri and Grieco, 2015). Gleason grading assigns a numerical grade (1-5) based on the architectural patterns of the tumour, with patterns 4 and 5 showing increasingly abnormal glandular architecture (Gleason, 1966). The sum of the primary grade assigned to the most prevalent pattern and the secondary grade assigned to the second most prevalent pattern provides the overall Gleason score (GS). If there is only one pattern, its grade is doubled to reach the score (Gleason, 1966). The GS is related to the biological behaviour of human PCs, so that men with tumours of GS 9 to 10 have a significantly worse prognosis than men with tumours of GS 8 or less in terms of biochemical recurrence (Pierorazio et al., 2013).

\section{Immunohistochemistry}

Immunohistochemistry (IHC) was performed using an indirect avidin-biotin-peroxidase procedure. All the incubations were performed at room temperature unless otherwise stated. Following dewaxing and rehydration of the sections, endogenous peroxidase was neutralized by incubation in $\mathrm{H}_{2} \mathrm{O}_{2} 3 \%$ in methanol for $30 \mathrm{~min}$. Antigen retrieval was achieved by submerging the sections in $0.1 \mathrm{M}$ sodium citrate $(\mathrm{pH}$ 6.0) and subsequent heating in a microwave oven for $15 \mathrm{~min}$ and cooling for $20 \mathrm{~min}$. The sections were pre-incubated with $5 \%$ normal goat serum and avidin-biotin blocking solution. Sections were then incubated with the primary rabbit polyclonal antiEphA3 antibody (Santa Cruz Biotechnology, Santa Cruz, California, USA; dilution 1 in 800) overnight and with a biotinylated secondary antibody (Vector Laboratories, Burlingame, California, USA) in phosphate buffered saline (PBS). Following incubation with peroxidase-conjugated avidin-biotin complex (Vector Laboratories) for $30 \mathrm{~min}$, as indicated by the manufacturer, peroxidase activity was 'visualized' by use of $3^{\prime}, 3^{\prime}$-diaminobenzidine for $5 \mathrm{~min}$ in the dark. Slides were then counterstained with Mayer's haematoxylin, dehydrated and mounted. As a negative control, primary antibodies were substituted with PBS, while normal canine skin was used as a positive control.

\section{Evaluation of Immunohistochemistry}

A semiquantitative immunohistochemical assessment was performed analysing 10 high-power fields $(\times 400)$. Samples were subdivided based on the protein expression levels into five ranges (semiquantitative score): 0 , no positive cells; $1+,>0$ to $\leq 10 \%$ positive cells; $2+,>10 \%$ to $\leq 25 \%$ positive cells; $3+,>25 \%$ to $\leq 50 \%$ positive cells; $4+,>50 \%$ to $\leq 75 \%$ positive cells; and $5+,>75 \%$ positive cells. The labelling intensity (qualitative score) was recorded as negative $(0)$ or positive on a scale from weak $(+)$ to strong $(+++)$.

\section{Statistical Analysis}

Differences between normal prostates, $\mathrm{BPH}, \mathrm{PC}$, each different subtype of $\mathrm{PC}$ and each different GS were assessed by the Chi-square test and considered to be significant at $P<0.005$.

\section{Results}

\section{Histopathology}

The histopathological examination confirmed that samples comprised of six normal prostates, 15 cases 
of BPH and 21 cases of PC. Four growth patterns of PG were differentiated: (1) cribriform $(n=12)$ (Fig. 1A) where ducts were expanded by neoplastic cells forming irregular fenestrae, often associated with central necrosis; (2) solid $(n=5)$ (Fig. 1B) formed of solid sheets, cord of cells or isolated individual cells without any specific growth patterns; (3) papillary $(n=2)$ (Fig. 1C) formed of dilated ducts containing papillary projections of neoplastic cells; and (4) small acinar/ductal $(n=2)$ (Fig. 1D) where neoplastic cells formed small acini and tubules.

Fifteen dogs were classified as having tumours with a GS of 10 (10 cribriform with necrosis; five solid), four as having tumours with a GS of 9 (two cribiform without necrosis in a mixed tumour, one papillary in a mixed tumour and one small acinar/ductal in a mixed tumour) and two as having tumours with a GS of 8 (one small acinar/ductal and one papillary).

\section{Immunohistochemistry}

Moderate cytoplasmic expression of EphA3 was demonstrated in few randomly scattered epithelial cells in five of six normal prostates (Fig. 2A). The percentage of positive cells ranged from 5 to $20 \%$, with a mean of $9.17 \pm 6.72 \%$. Other EphA3-positive cells included endothelial cells, fibroblasts and smooth muscle cells within the stroma.

All cases of BPH were positive with weak (5/15) or moderate (10/15) labelling intensity (Fig. 2B). The percentage of positive cells ranged from 5 to $35 \%$, with a mean of $20 \pm 8.28 \%$.

In all PC samples, the antibody showed diffuse and moderate (4/21) to strong (17/21) labelling (Figs. 2A and $3 \mathrm{~B})$. In two cases, membranous expression was also evident (Fig. 3G). The mean percentage of neoplastic epithelial cells labelled was $89.28 \pm 5.18 \%$. When present, cancer glands circumferentially encircling a nerve fibre (perineurial invasion) were strongly positive (Fig. 3D).

A significant difference in the semiquantitative score was observed between normal/hyperplastic prostates and $\mathrm{PCs}(P<0.005)$. Labelling intensity and percentage of positive cells were similar in all histological subtypes without any significant differences.

The mean percentage of positive cells in tumours of GS $10(92.55 \pm 7.82 \%)$ and GS $9(91.47 \pm 5.67 \%)$ were slightly higher than in tumours of GS 8 $(89 \pm 6.11 \%)$, although the difference was not significant.

\section{Discussion}

The present study represents the first investigation of EphA3 expression in a canine solid tumour, and specifically in canine prostate cancer. The increased immunohistochemical labelling for EphA3 in canine PG cells compared with normal and hyperplastic
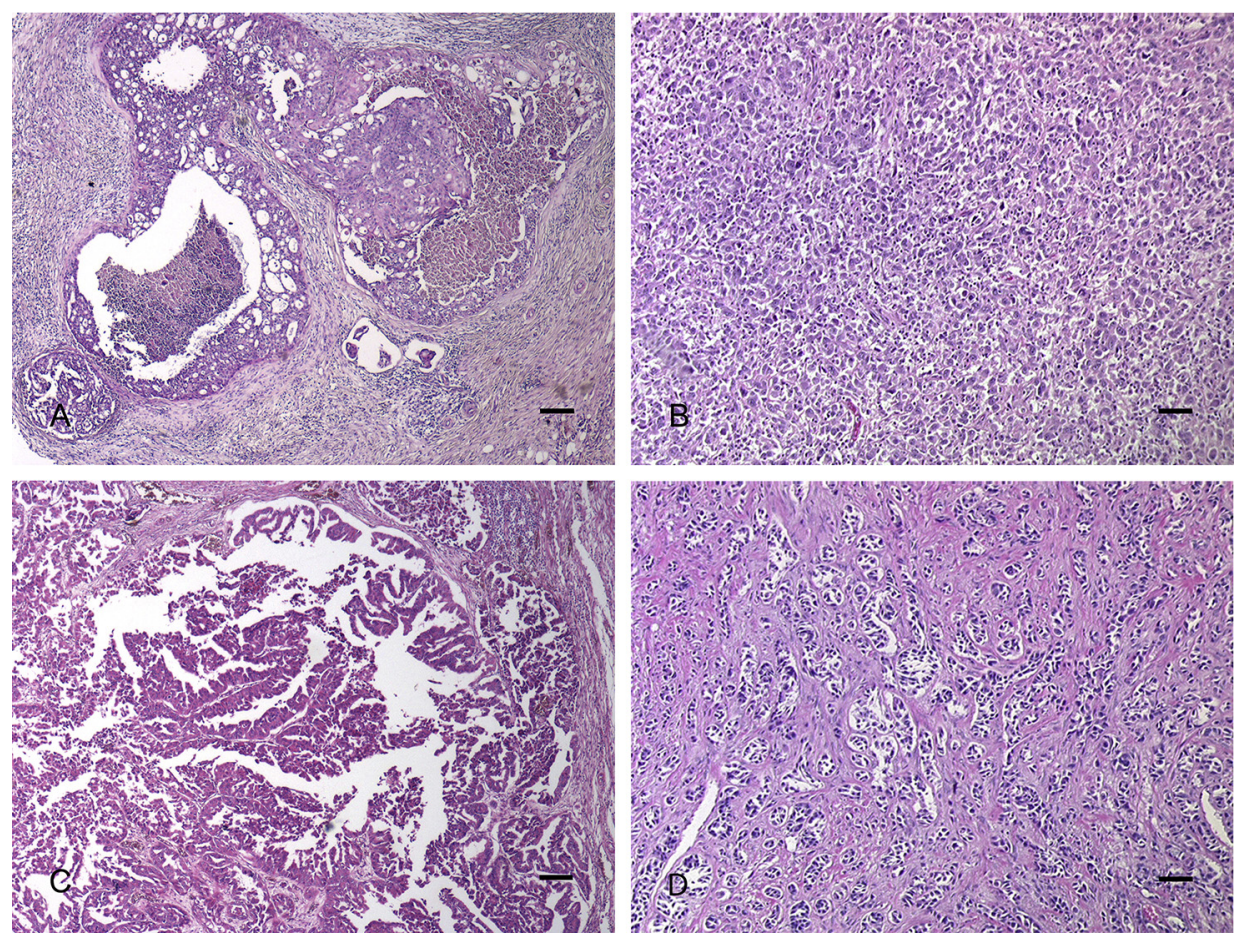

Fig. 1. Histological growth pattern of canine prostatic carcinoma. (A) Cribriform with central necrosis. HE. Bar, $200 \mu \mathrm{m}$. (B) Solid undifferentiated. HE. Bar, $50 \mu \mathrm{m}$. (C) Papillary. HE. Bar, $200 \mu \mathrm{m}$. (D) Small acinar/ductal. HE. Bar, $50 \mu \mathrm{m}$. 

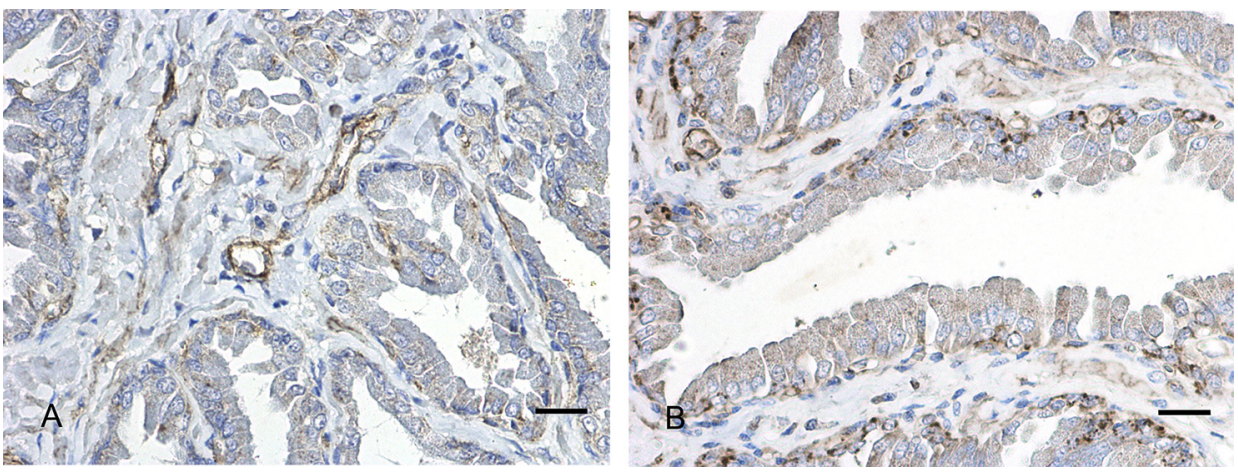

Fig. 2. (A) Normal prostate showing randomly scattered basal cells with strong cytoplasmic EphA3 expression. Note the positive reaction of endothelial cells and fibroblasts within the stroma. IHC. Bar, $80 \mu \mathrm{m}$. (B) Benign prostatic hyperplasia showing strong EphA3 expression in the basal cell layer. IHC. Bar, $80 \mu \mathrm{m}$.

canine prostates suggests that EphA3 may play a role in the carcinogenesis of prostate cancer in dogs, as already demonstrated in human hepatic cancer, lung cancer, renal cancer, colorectal cancer, melanoma, sarcoma, rhabdomyosarcoma, glioblastoma and gastric cancer (Chiari et al., 2000; Hafner et al., 2004; Wimmer-Kleikamp and Lackmann, 2005; Clifford et al., 2008; Bae et al., 2009; Valsesia et al., 2011; Xi et al., 2012; Day et al., 2013).

Similar findings have been obtained by Wu et al. (2014) in human prostate cancer, with EphA3 expression detected in PC tissues and not in adjacent normal tissues or BPH tissue specimens, as well as in PC cell lines with different metastatic potential, namely LNCaP (androgen-dependent, non-metastatic and weakly tumourigenic) and C4-2B (androgen-independent, metastatic) cells.

In normal and hyperplastic prostates, EphA3 is mainly expressed by few cells of the basal compartment that possesses self-renewal capacity (Goldstein et al., 2010). Basal cells are less differentiated and proliferate more frequently compared with secretory cells (Bonkhoff et al., 1994), and their role in prostatic carcinogenesis has been discussed in dogs, with 25\% of canine PCs expressing the basal cell marker cytokeratin 5 (Akter et al., 2015). In human solid tumours,
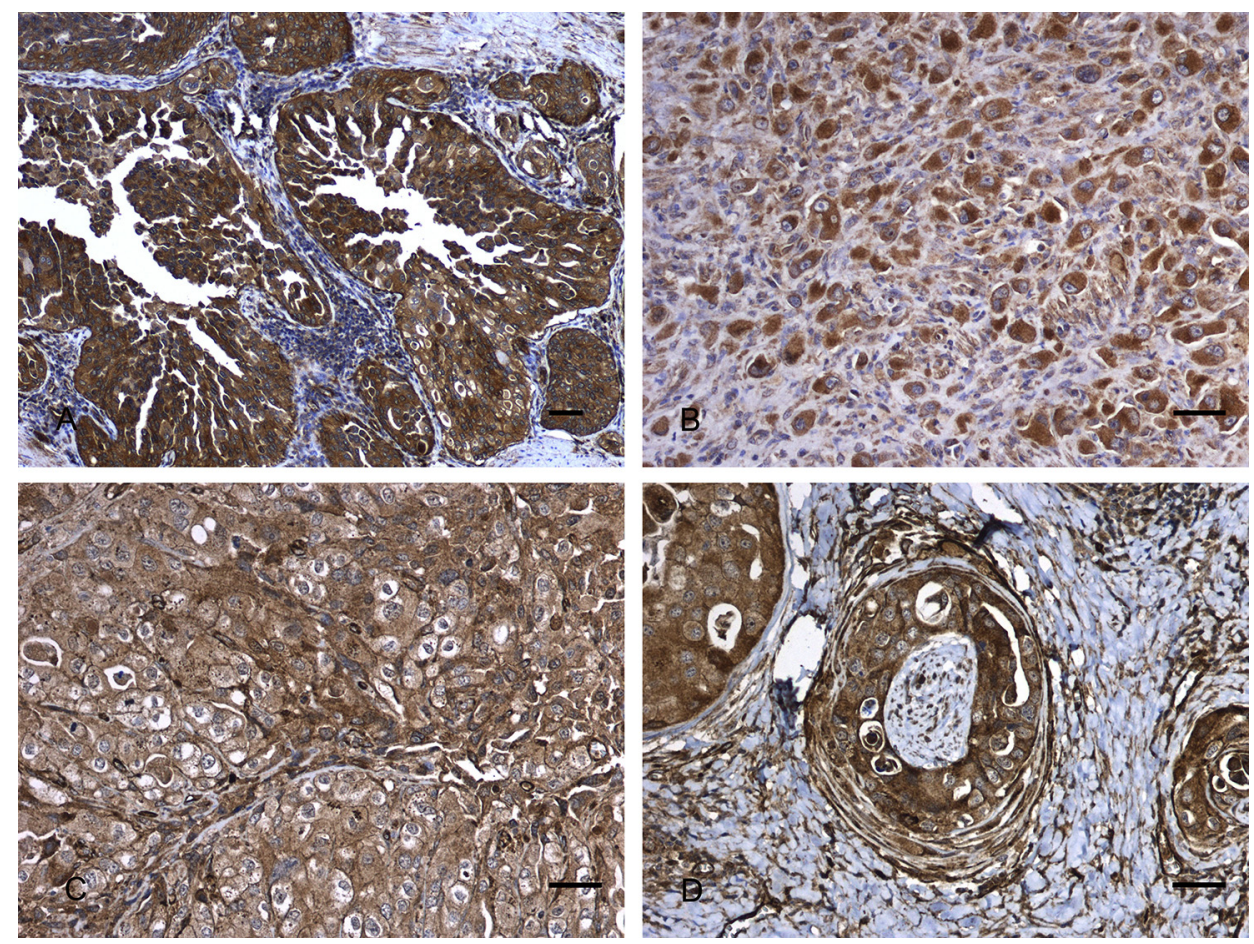

Fig. 3. Immunohistochemical expression of EphA3 in canine prostatic carcinomas (PCs). (A) Cribriform PG. IHC. Bar, $50 \mu \mathrm{m}$. (B) Solid PC. IHC. Bar, $100 \mu \mathrm{m}$. (C) Cribriform PC showing cytoplasmic and membranous labelling. IHC. Bar, $100 \mu \mathrm{m}$. (D) Neoplastic cells encircling a nerve fibre (perineurial invasion) showing diffuse cytoplasmic expression of EphA3. IHC. Bar, $100 \mu \mathrm{m}$. 
EphA3 is expressed by both cancer stem cells and mesenchymal stem cells within the tumour stroma, thereby indicating a role for EphA3 in both tumour initiation and long-term maintenance (Janes et al., 2014). This supports the preferential expression of EphA3 in the less differentiated and stem cell-like canine prostatic basal cell layer.

The present results reveal that EphA3 expression is not correlated with the histological subtype of canine prostate cancer or with the GS. However, canine PC is a highly aggressive tumour, mostly of GS 10 (Palmieri and Grieco, 2015) and in the present study only three categories of GS $(8,9$ and 10) were considered. No information is available on the expression pattern of EphA3 in low GS prostatic cancers, although a slightly increased EphA3 was observed in tumours of GS 10 and GS 9 compared with those of GS 8. A positive correlation between the levels of EphA3 and the GS of PCs has been identified in human clinical specimens (Wu et al., 2014). This is consistent with data from melanoma and breast cancer, where EphA3 is reported to be highly expressed in metastatic lesions, but not in the primary tumours (Easty and Bennett, 2000; Vecchi et al., 2008). In colorectal cancer, the expression of EphA3 positively correlated with tumour size, histological grade, depth of invasion, lymph node metastasis, distant metastasis and TNM stage ( $\mathrm{Xi}$ and Zhao, 2011). Regarding PCs, EphA3 has been identified as one of several genes associated with androgen independence, with expression of the gene being increased 39-fold in androgen-independent PC cells (LNCaPC33) compared with in androgen-dependent PG cells (LNCaP-C33) (Singh et al., 2008). Human PC is initially androgen sensitive and relapses after androgen deprivation therapy as a hormonerefractory, highly undifferentiated, highly aggressive and heterogeneous tumour (Shah et al., 2004). In dogs, $\mathrm{PC}$ is not responsive to androgen deprivation therapy and has an undifferentiated morphology and aggressive behaviour, resembling the refractory phase of human PC (Lai et al., 2008). Therefore, the increased expression of EphA3 in the present prostatic samples is consistent with the androgen-independent feature of both canine and human PC.

Accumulated research has shown that the aberrant regulation of EphA3 and its genetic alteration are involved in the development and progression of various cancers (Bae et al., 2009). In many cancers, especially haematopoietic tumours, abnormal EphA3 expression is predominantly overexpression of nonmutated EphA3 protein (Keane et al., 2012). The high level of expression of EphA3 in canine prostate cancer might be due to a mechanism of gene amplification and overexpression or the effect of its sequence alteration on transcriptional control, such as DNA methylation.

Based on these preliminary findings, we suggest that EphA3 may be a potential oncogene that has an important role in the development and malignant progression of canine $\mathrm{PC}$ and, therefore, may be a useful therapeutic target. The potential of EphA3 as a target for cancer therapy has been demonstrated previously (Brantley et al., 2002; Vearing et al., 2005; Vail et al., 2014). Soluble EphA3-Fc receptors and antiEphA3 antibody can inhibit proliferation of tumour cells and decrease tumour volume in vivo (Brantley et al., 2002; Vearing et al., 2005). Moreover, targeting EphA3 inhibits cancer growth by disrupting the integrity and function of newly formed tumour stroma and microvasculature (Vail et al., 2014).

\section{Acknowledgments}

This work was supported by the John and Kibble Trust grant (2014) and the Dr William Peter Richards Bequest for Research in Veterinary Pathology (2014).

\section{References}

Akter SH, Lean FZX, Lu J, Grieco C, Palmieri C (2015) Different growth patterns of canine prostatic carcinoma suggests different models of tumor-initiating cells. Veterinary Pathology, 2, 1027-1033.

Bae HJ, Song JH, Noh JH, Kim JK, Jung KH et al. (2009) Low frequency mutation of the ephrin receptor A3 gene in hepatocellular carcinoma. Neoplasm, 56, 331-334.

Bonkhoff H, Stein U, Remberger K (1994) The proliferative function of basal cells in the normal and hyperplastic human prostate. Prostate, 24, 114-118.

Brantley DM, Cheng N, Thompson EJ, Lin Q, Brekken RA et al. (2002) Soluble EphA receptors inhibit tumor angiogenesis and progression in vivo. Oncogene, 21, $7011-7026$.

Chiari R, Hames G, Stroobant V, Texier C, Maillere B et al. (2000) Identification of a tumor-specific shared antigen derived from an Eph receptor and presented to CD4 T cells on HLA class II molecules. Cancer Research, 60, 4855-4863.

Clifford N, Smith LM, Powell J, Gattenlohner S, Marx A et al. (2008) The EphA3 receptor is expressed in a subset of rhabdomyosarcoma cell lines and suppresses cell adhesion and migration. Fournal of Cell Biochemistry, $\mathbf{1 0 5}, 1250-1259$.

Cornell KK, Bostwick DG, Cooley DM, Hall G, Harvey HJ et al. (2000) Clinical and pathological aspects of spontaneous canine prostatic carcinoma: a retrospective analysis of 76 cases. The Prostate, 45, $173-183$.

Day BW, Stringer BW, Al-Ejeh F, Ting MJ, Wilson J et al. (2013) EphA3 maintains tumourigenicity and is a 
therapeutic target in glioblastoma multiforme. Cancer Cell, 23, 238-248.

Easty DJ, Bennett DC (2000) Protein tyrosine kinases in malignant melanoma. Melanoma Research, 10, 401-411.

Eble JN, Sauter G, Epstein JI, Sesterhenn IA (2004) WHO Classification of Tumors: Pathology and Genetics of Tumors of the Urinary System and Male Genital Organs. IARC Press, Lyon, pp. 159-216.

Epstein JL, Allsbrook WC Jr., Amin MB, ISUP Grading Committee (2005) The 2005 International Society of Urological Pathology (ISUP) consensus conference on Gleason grading of prostatic carcinoma. Americal fournal of Surgical Pathology, 29, 1228-1242.

Fox BP, Tabone GJ, Kandpal RP (2006) Potential clinical relevance of Eph receptors and ephrin ligands expressed in prostate carcinoma cell lines. Biochemical and Biophysical Research Communications, 342, 1263-1272.

Gleason DF (1966) Classification of prostatic carcinomas. Cancer Chemotherapeutics, 50, 125-128.

Goldsmid SE, Bellenger CR (1991) Urinary incontinence after prostatectomy in dogs. Veterinary Surgery, 20, $253-256$.

Goldstein AS, Huang J, Guo C, Garraway IP, Witte ON (2010) Identification of a cell of origin for human prostate cancer. Science, 329, 568-571.

Hafner C, Schmitz G, Meyer S, Bataille F, Hau P et al. (2004) Differential gene expression of Eph receptors and ephrins in benign human tissues and cancers. Clinical Chemistry, 50, 490-499.

Himanen JP, Saha N, Nikolov DB (2007) Cell-cell signaling via Eph receptors and ephrins. Current Opinions in cell Biology, 19, 534-542.

Janes PW, Slape CI, Farnsworth RH, Atapattu L, Scott AM et al. (2014) EphA3 biology and cancer. Growth Factors, 32, 176-189.

Keane N, Freeman C, Swords R, Giles FJ (2012) EPHA3 as a novel therapeutic target in the haematological malignancies. Expert Review of Hematology, 5, 325-340.

Kilpatrick TJ, Brown A, Lai C, Gassmann M, Goulding M et al. (1996) Expression of the Tyro4/Mek4/Cek4 gene specifically marks a subset of embryonic motor neurons and their muscle targets. Molecular Cell Neuroscience, 7, $62-74$

Lai C-L, van den Ham R, van Leenders G, van der Lugt J, Mol JA et al. (2008) Histopathological and immunohistochemical characterization of canine prostate cancer. The Prostate, 68, 477-488.

Palmieri C, Grieco V (2015) Proposal of Gleason-like grading system of canine prostate carcinoma in veterinary pathology practice. Research in Veterinary Science, 103, 11-15.

Palmieri C, Lean FZ, Akter SH, Romussi S, Grieco V (2014) A retrospective analysis of 111 canine prostatic samples: histopathological findings and classification. Research in Veterinary Science, 97, 568-573.

Pasquale EB (2005) Eph receptor signaling casts a wide net on cell behaviour. Nature Reviews Molecular Cell Biology, 6, $462-475$.
Pasquale EB (2008) Eph-ephrin bidirectional signaling in physiology and disease. Cell, 133, 38-52.

Pierorazio PM, Walsh PC, Partin AW, Epstein JI (2013) Prognostic Gleason grade grouping: data based on the modified Gleason scoring system. B FU International, 111, 753-760.

Shah RB, Mehra R, Chinnaiyan AM, Shen R, Ghish DM et al. (2004) Androgen-independent prostate cancer is a heterogeneous group of diseases: lessons from a rapid autopsy program. Cancer Research, 64, 9209-9216.

Singh AP, Bafna S, Chaudhary K, Venkatraman G, Smith L et al. (2008) Genome-wide expression profiling reveals transcriptomic variation and perturbed gene networks in androgen-dependent and androgen-independent prostate cancer cells. Cancer Letters, 259, 28-38.

Turrel JM (1987) Intraoperative radiotherapy of carcinoma of the prostate gland in ten dogs. Fournal of the American Veterinary Medical Association, 190, 48-52.

Vail ME, Murone C, Tan A, Hii L, Abebe D et al. (2014) Targeting EphA3 inhibits cancer growth by disrupting the tumor stromal microenvironment. Cancer Research, 74, 4470-4481.

Valsesia A, Rimoldi D, Martinet D, Ibberson M, Benoglio P et al. (2011) Network-guided analysis of genes with altered somatic copy number and gene expression reveals commonly perturbed pathways in metastatic melanoma. PLoS One, 6, el8369.

Vearing C, Lee FT, Wimmer-Kleikamp S, Spirkoska V, To C et al. (2005) Concurrent binding of anti-EphA3 antibody and ephrin-A5 amplifies EphA3 signaling and downstream responses: potential as EphA3specific tumor-targeting reagents. Cancer Research, 65, 6745-6754.

Vecchi M, Confalonieri S, Nuciforo P, Vigano MA, Capra M et al. (2008) Breast cancer metastases are molecularly distinct from their primary tumors. Oncogene, 27, 2148-2158.

Wimmer-Kleikamp SH, Lackmann M (2005) Ephmodulated cell morphology, adhesion and motility in carcinogenesis. IUBMB Life, 57, 421-431.

Wu R, Wang H, Wang J, Wang P, Huang F et al. (2014) EphA3, induced by PC-1/PrLZ, contributes to the malignant progression of prostate cancer. Oncology Reports, 32, 2657-2665.

Xi H-Q, Zhao P (2011) Clinicopathological significance and prognostic value of EphA3 and CD133 expression in colorectal carcinoma. Fournal of Clinical Pathology, 64, 498-503.

Xi H-Q, Wu X-S, Wei B, Chen L (2012) Aberrant expression of EphA3 in gastric carcinoma: correlation with tumor angiogenesis and survival. Fournal of Gastroenterology, 47, 785-794. 